\section{Lurismo Rural no Vale do Paraíba Paulista: Estudo de Modelos}

\section{Pedro de Alcântara Bittencourt César Beatriz Veroneze Stigliano ${ }^{2}$}

RESUMO: Traça um breve panorama sobre a região do vale do Paraíba paulista. Analisa o turismo rural como possibilidade de desenvolver o espaço rural. Discorre sobre a utilização da bibliografia e experiências internacionais, principalmente dos países europeus de cultura latina, na construção de um modelo de turismo no espaço rural brasileiro, além de experiências nacionais.

PALAVRAS-CHAVE: turismo rural, vale do Paraíba, bibliografia acadêmica, Projeto Leader, Projeto Rurbano.

ABSTRACT: The present article presents an overview • the Paraiba Valley in the state of São Paulo. It analyzes the rural tourism as a possibility of developing the rural space. It refers to the use of international bibliography and experiences, mainly of the European countries of Latin culture, in the construction of a model of tourism in the Brazilian rural space. It also comments some national experiences.

KEYWORDS: rural tourism, Paraíba Valley - São Paulo State (Brazil), academic bibliography, Leader Project, Rurbano Project.

\section{Região Vale do Paraíba}

Natipificação agrária do vale do Paraíba encontram-se traços da cafeicultura de outrora. Esta rubinácia (Lemos, 1999:133) foi introduzida "no começo do século

\footnotetext{
1. Arquiteto e mestrando em Turismo pela UNIBER@. Aluno especial da Escola de Comunicaçêes e Artes Universidade de São Paulo e especialista em planejamento e marketing turístico.

E-mail:p.bittencourt@mailandnews.com

2. Bacharele mestrandaem Turismo pela Escola de Comunicaç̧es e Artes da Universidade de São Paulo (ECA/USP), Professora colaboradora do curso de Turismo da ECA/USP. Consultora em Planejamento Turístico

E-mail: beatriz@backpacker.com
}

XIX, subindo o rio até a proximidade de Jacareí (...)", dirigindo-se para a região de Campinas e Jundiaí, antes da metade do século. Este processo legou um novo modo de vida, transformando a antiga sociedade colonial existente.

Esta região é o testemunho vivo de uma sociedade escravocrata cafeicultora, que vivia em uma espécie de "agrovila", com aspectos marcantes como, por exemplo, um pequeno comércio, uma relação social e religiosa de sincretismo advindo da união dos cultos africanos e cristãos, bem como uma capela para a manifestação da religiosidade católica. Hoje, com suas características peculiares à região, restaram casarios, capelas, senzalas, casas de moenda e de armazenagem, entre outros elementos, no meio citadino ou rural, com utilização variada.

O turismo pode ser uma forma para desenvolver o espaço rural do vale do Paraíba, que vivencia um momento de ociosidade em suas estruturas fundiárias, caracterizado, principalmente, pelo êxodo de seus moradores. Apresenta, como fator predominante para o desenvolvimento do turismo rural, uma paisagem formada de antigas fazendas, criadas do parcelamento das sesmarias e exploradas à exaustão no período do ciclo cafeeiro, posteriormente subutilizadas para a pecuária. Hoje, muitas delas estão abandonadas.

Pellegrini Filho (1997:77), em uma breve listagem do Patrimênio Natural do país, elenca a região do vale do Paraíba pela sua Serra da Mantiqueira, onde se "encontram cidades com clima puro, altitudes que chegam a ultrapassar $2.000 \mathrm{~m}$ ". Também lembra, em um inventário intitulado Turismo Rural, a presença das "fazendas cafeeiras do Vale do Paraíba" (1997:81-82). Em um levantamento do SPHAN-SP, na década de 70, foram inventariadas cerca de 500 propriedades agrárias com características e condições "ideais para serem recicladas", em São Luiz do Paraitinga, Lagoinha, Pindamonhangaba, Bananal, Areias, São José do Barreiro, no Estado de São Paulo, além de Itajubá e Varginha em Minas Gerais e Vassouras e Valença no Estado do Rio de Janeiro, entre outras. O perfil dessas fazendas associa os atrativos naturais com os "atrativos culturais", que reportam ao século XIX Localiza ainda, na região, a Fundação Nacional do Tropeirismo, com sede em Silveiras, que incentiva o turismo rural e educativo.

Esta característica peculiar do espaço agrário valeparaibano diferencia-o das regiões-modelo de turismo rural tipificado no caso brasileiro, como Lajes, em Santa Catarina, e a região de Domingos Martins, no Espírito Santo. Porém, aproxima-se de modelos adotados no continente europeu, especialmente em países de cultura latina (Mazuel, 2000).

\section{Utilização de Modelos}

O estudo do turismo rural descnvolve-se entre uma dialética sobre o uso da literatura nacional e a estrangeira. Nesta questão, Rodrigues (2000:52) posiciona que a imprecisão conceitual do turismo está vinculada aos estrangeirismos que 
"mostram modalidades distintas no que concerne ao turismo em espaço rural, sem afinidade de critério de classificação".

Convém ressaltar que o turismo rural é desenvolvido segundo as características peculiares de seu meio e, especificamente no Estado de São Paulo, apresenta inúmeras diferenciações entre as diversas regiões. As características que são marcantes para a composição e caracterização deste espaço são seus fatores topográficos e morfológicos, climáticos, culturais e etnológicos, entre outros componentes das regiões turísticas.

Quanto à utilização do modelo europeu no país, pontua Pellegrini Filh (1997:110) que a Itália, a França e a Espanha "possuem larga experiência na reciclagem de programas (a função) de seu patrimônio edificado" como os castelos franceses, o turismo de habitação de Portugal, em que o turista fica "hospedado cm antigas fazendas senhoris, em quintas", entre outros espaços para manter e "estabelecer contato com os traços culturais". A mesma linha de raciocínio é compartilhada por Tulik (1997:142), que relata que

todos os interessados no Turismo Rural muito podem aprender com as experiências vivenciadas em outros paises que resultam na profusāo de conceitos e na adoçāo de estratégias, ambos diversificados conforme as especificidades locais de seus recursos físicos e humanos. Todos podem lucrar como apoio conceitual metodológico e estratégico oferecido pela avaliaçāo de erros e acertos e, evidentemente, com a adaptaçāo dessas práticas à realidade brasileira.

Dissonante desta linha, Roque e Vivian (2000) afirmam que

as atividades relacionadas ao turismo no meio rural em outros paises não podem ser comparadas ou servirem de modelo para o turismo rural brasileiro, pois estamos trabalhando com realidades ambientais diferentes.

Condicionam como necessário para o seu desenvolvimento o acúmulo de

informaçōes que possam contribuir no estabelecimento de estratégias eficientes e eficazes. Isto permite inferir que o sistema de informaçāo na propriedade torna-se base para o bom gerenciamento.

Pode-se encontrar uma bibliografia "razoável" para ser analisada, comparada e personalizada dentro desta realidade, se não se restringir apenas às experiências nacionais. Acredita-se que as experiências estrangeiras podem contribuir à pratica no Brasil.
Segundo o pesquisador espanhol Gómez (1983:66)

o turismo nāo é exclusivamente um componente da qualidade de vida da populaçāo urbana, mas também um instrumento para a revitalizaçāo do patrimônio sociocultural e reaquecimento da economia local.

Ao pontuar esta questão, considera o espaço rural como detentor de um acervo e de um legado cultural representativos. O modelo agrário de baixa produtividade socioeconômica encontrado no vale do Paraíba é análogo às características pontuadas.

Outras características apresentadas pelo autor, como a segmentação turística preponderantemente familiar, as raízes agrárias da sociedade urbana e a existência de casarios, que devem ser recuperados, são semelhantes à nossa realidade.

Gómez (1983:72) propõe, então, como "modelo ou estratégias do desenvolvimento turístico no espaço rural", a harmonização de ações de conservação e de desenvolvimento dos recursos turísticos, a criação de uma oferta de alojamento e de lazer não concentrada e de pequena escala e coordenada pelo local e pelo comércio, a criação de atividades ao ar livre e o estimulo do autêntico diálogo entre a população rural e a urbana. Estas atitudes e gestões turísticas devem partir das comunidades locais. A recuperação e revitalização dopatrimônio rural imobiliário devem permitir a criação de uma oferta personalizada e de qualidade. No vale do Paraiba, pode ser adotado este perfil de desenvolvimentoturístico, que se mostra pertinenteà realidade local e já é verificado em alguns casos.

A Comissão Européia da Organização Mundial de Turismo (CEU) - Comissão Européia de Viagens (ETC) (1996) relata, em seu seminário, que

as áreas rurais européias sāo uma conseqüência dos grandes espaços livres criados pelos homens das antigas florestas de outrora e hoje são uma realidade ecológica,

que não é diferente da realidade brasileira. Lembra, ainda, que países como Áustria, França, Itália e Suíça são pioneiros neste campo e hoje possuem um grande acervo de experiência e de bibliografia.

\section{Experiências Referenciais}

Dentro desta linha de pesquisa e desenvolvimento de trabalho, têm-se os Projeto Leader, na Europa, com suas versões e adaptações, e o Projeto Rurbano, brasileiro, como duas experiências, entre outras, que são referências na área de turismo rural. 
O Projeto Leader, sigla francesa de "Relações entre Atividades para o Desenvolvimento da Economia Rural", é uma iniciativa da União Européia, que foi aplicado em duas etapas com os nomes de Leader I, entre os anos de 1991 e 1994 , e Leader II, subseqüiente ao anterior, encerrado em 1999.

Especificamente, o Leader II tem como objetivo o patrocínio de atividades inovadoras, do poder público e privado da comunidade local envolvida, desde que em zonas rurais.

Em linhas gerais, essas atividades foram de capacitação de recursos humanos e "remodelagem" do meio rural, através de apoio técnico para o desenvolvimento formação e orientação para a contratação de profissionais; o estímulo ao turismo rural, às pequenas empresas, ao artesanato; a valorização dos produtos agrícolias e a conservação e melhora do meio ambiente, entre outras iniciativas para um melhor posicionamento destas anteriores.

Este projeto contou com o financiamento conjunto de diversos órgãos de fomento, sendo que a União Européia ficou com um terço do financiamento total e o restante foi dividido pelas diversas esferas nacionais, além dos agentes privados.

Algumas de suas características são:

- todo projeto é definido segundo a especificidade de cada região;

- as decisões partem da comunidade envolvida;

- incentivar o associativismo entre os envolvidos;

- qucbrar paradigmas na tomada das decisões;

- as ações são sempre integradas;

- descentralização para o gerenciamento financeiro;

- organização de redes e de cooperativas transnacionais.

No caso específico da Espanha, foi elaborado o Programa Operacional de Desenvolvimento Econômico de Zonas Rurais (Proder), como um programa similar ao Leader, diferenciando-se somente quanto a sua forma de gestão, com as suas peculiaridades, derivado do programa nacional Marco Comunitario de Apoyo de los Fondos Estructurales e coordenado pelo Ministério da Agricultura, Pesca e Alimentação, do governo espanhol.

Este programa desenvolve, mais especificamente, ações na área de turismo, pela própria característica cconômica do país, como valorizar o patrimônio rural e investimento para o incentivo do agroturismo, previstas em seus objetivos primários

Apesar dos 101 grupos de ação do Proder aplicarem parcialmente os métodos do Leader, a diferença deste dois projetos está na criação da Cooperativa Transnacional, por parte deste último.

A unidade espanhola do Leader é uma estrutura de impulsão, informação e difusão dos grupos de ação local, denominada GAL.

Em âmbito europeu, o Projeto Leader "analisa as diversas soluções ao problema econômico e social das áreas menos desenvolvidas da Europa" (Giangordano, 1997:22), como o turismo rural.
No total, o projeto mantém interesse em

217 zonas rurais européias, heterogêneas quanto a sua paisagem, cultura e tradiçōes, mas homogêneas por serem áreas de subdesenvolvimento e com baixa densidade demográfica (Giangordano, 1997:24).

O Projeto Rurbano, desenvolvido na Universidade de Campinas (Unicamp) no Núcleo de Economia Agrícola (NEA), é um ponto de referência na área rura brasileira. Tem como linha programática: políticas agrícolas comprovadas e a inserção do Brasil no comércio mundial; formação de preços na agricultura; complexos agroindustriais; novas tecnologias na agricultura; Relações de trabalho, emprego e política no campo; propriedade; mercado de terra e política agrária; economia do meio ambiente e agricultura sustentável; com a participação efetiva do prof. dr. José Francisco Graziano da Silva, entre outros que, com uma grande produção acadêmica, pesquisam o espaço rural e inserem a atividade turística neste.

Baseando-se nos números primários da Pesquisa Nacional por Amostra de Domicílio (PNDA), esta equipe de trabalho cria uma série de analogias, tendo como objeto de estudo a temática do homem no campo, reconstruindo "séries históricas para o período $1981 / 95$ " a partir destes dados.

Nesta linha, desenvolve uma série de trabalhos como Ocupação das famílias agrícolas e rurais no Brasil; Políticas não agrícolas para o novo rural brasileiro; Turismo em áreas rurais, suas possibilidades e limitações para o Brasil, entre muitos outros trabalhos, que têm contribuído para a formação da bibliografia nacional.

Porém, devemos conhecer experiências em outros países, como:

- SRLA (Servicios de Reservas Loirirs Accueil) criada do interesse dos prestadores espanhóis de serviços rurais se associarem;

- GRAND D criada também na Espanha para agregar a prática do turismo em áreas naturais;

- Gitê de Franice Services, com a sua experiência em pequenos alojamentos franceses, com "qualidade por excelência",e com seu material promocional: Gitês Rurax, Chambres et Tables d'Hôtel, Gitês d'Etape et Camping à la Ferme, Gitês et lógis de Pêche.

Outro exemplo da Espanha para o turismo, inclusive para o turismo rural, é o Plan Integral de Calidad del Turismo Español (PICTE), na canalização de esforços para que os setores público e privado ofereçam um produto de qualidade e com alta competitividade para a demanda internacional.

Como proposta de desenvolvimento até o ano de 2006, ele propõe desenvolver paralelos com outras iniciativas de desenvolvimento turístico e visa a criação de ofertas, tanto básicas como complementares, além de remodelar a oferta existente e modernizar a infra-estrutura pública. 


\section{Consideraçōes Finais}

Deve-se ter consciência de que a literatura local não oferece experiências e argumentos suficientes para alcançar uma autonomia em relação à literatura estrangeira. Assim, os estudos de Lengen (1996), que cria uma "cartilha" para as construções rurais, de Mowforth e Munt (1998), com exemplos relevantes sobre a conservação espacial e ambiental, oferecendo uma visão global do turismo com exemplos específicos de sustentabilidade e de "terceiro mundo", de Crosby (1994), que analisa o produto turístico, suas formas e análise de espaço, além das experiências dos pesquisadores como Cavaco (2000) e Mazuel (2000), muito presentes em nosso meio acadêmico, entre outros exemplos, podem contribuir como literatura a ser utilizada como referencial.

O vale do Paraíba apresenta características análogas a de alguns modelos europeus, como a necessidade de revitalização do espaço rural / agrário, a diminuição do êxodo rural, assentando o trabalhador, criação de atividades complementares à atividade agrícola e, principalmente, a melhora de oportunidade do trabalhador do campo, quer seja do lavrador quer seja ao médio proprietário. Além disso, há muito a ser analisado, questionado e referenciado de experiências como o Projeto Leader. Deve-se sim, criar convênios e intercâmbios para que fiquem esses modelos mais próximos da nossa realidade.

\section{Referências Bibliográficas}

CAVACO, Carminda. 2000. Turismo, comércio edesenvolvimento rural. In: ALMEIDA, Joaquin Anécio, RIEDL; Mário

(Org.). Turismo rural, ecologia, lazer e desenvolvimento. Bauru: Edusc.
COMISSÁO EUROPÉIA DA ORGANIZAÇÃO MUNDIAL DE TURISMO - COMISSĀO EUROPÉIA DE VIAGENS. 1996. Le tourism rural, une solution pour l'emploi le developpement et l'environnemt. [Israel]: Ministery of tourism Israel.

CROSBY, Arturo (Org.). 1994. Interpretacion ambiental y turismo rural. Madri: Cefat.

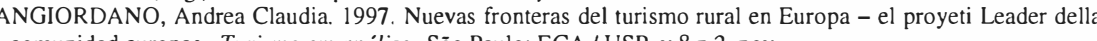

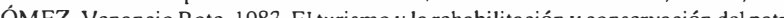

Enio rural en Espanha. Estudios

(1999. The geography of tourismand recreation: environment, place and space. Londres: Routledge.

列 ADER. Liason entre Action de Développement de L'Economie Rurale. Disponível em <http://redrural.tragsatec.es.>

LEMOS, Carlos A. C. 1999. Casa Paulista: história das moradias anterior ao ecletismo trazido pelo café. São Paulo:

LENGEN, Johann van. 1996. Manual do arquiteto descalço. Rio de Janeiro: Tiba.

MAZUEL, Luc. 2000. Patrimônio cultural e turismo rural: o exemplo francês. In: ALMEIDA, Joaquin Anécio, RIEDL, Mário (org.). Turismo rural, ecologia, lazer e desenvolvimento. Bauru: Edusc.

MOWFORTH, Martin e MUNT, Ian. 1998. Turism and sustainability in the third world. Londres: Routledge.

PELLEGRINI FILHO, Américo. 1997. Ecologia. cultura e turismo. Campinas: Papirus.

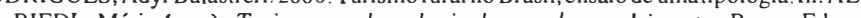

In CONGRESSO BRASILEIRODEECONOMIAE SOCIOLOGIA RURAL 37. [2000] Anais Brasília

TULIK. Olga 1997. Do conceito às estratégias para o desenvolvimento do turismo rural. In: RODRIQUES, Adyr Balastreri. Turismo, desenvolvimento local. São Paulo: Hucitec.

Recebido em 12/2/200

Aprovado em 2/4/2001 